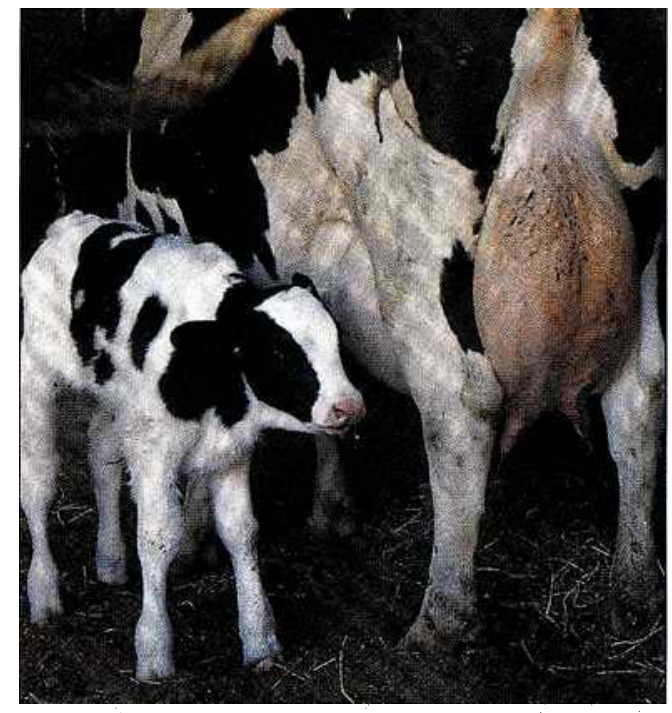

Density of immunoglobulins that pass from the dairy cow to the calf in the first milk (colostrum) is important in the calf's development of high levels of passive immunity. This study shows that specific gravity of the first milk is a better gauge of immunoglobulin density than conventional observation. Better use of colostrum may reduce the incidence of early calfhood disease and the need for antibiotics or other antimicroblals.

Colostrum, the first milk from a dairy cow, is enriched with immunoglobulins which impart increased immunity to the newly born calf. Although the immunity that develops is passive and its strength decreases with time and challenges, it helps the calf resist microbial invaders until its own active immune system develops. With a strong passive immunity, the calf's survival is less dependent on disease treatment with antibiotics and other manufactured antimicrobials.

Early work by researchers suggests that (1) colostrum from individual cows can vary in its content of immunoglobulins and (2) the level of passive immunity developed in the calf is directly related to the concentration of immunoglobulins in colostrum rather than the total quantity the calf ingests.

W. A. Fleenor and G. H. Stott of the University of Arizona found that the specific gravity of the colostrum is directly related to its ability to increase the level of immunoglobulins in the calf 's blood. (Specific gravity is the ratio of the density of colostrum to the density of water at a certain temperature, when both are weighed in air.) A modified hydrometer, called a colostrometer, was developed to help dairy producers measure the specific

\section{Specific gravity: a better test of first-milk quality}

\author{
Don A. Toenjes a Suzanne Strasser a Don L. Bath
}

gravity of colostrum and evaluate the concentration of immunoglobulins in colostrum before feeding it to a newborn calf.

Despite the depth of work on this subject, dairy producers generally feel either that colostrum is all the same or that older cows produce better colostrum and that yellow colostrum is best. The opportunity to verify these concepts was presented at the LaGrone Holstein Dairy in Glenn County, California.

\section{Methods}

In this study, we used colostrum milk from 714 calvings that occurred in a 390- cow dairy herd between the winter of 1984 and the spring of 1987 . The cows at calving were divided into three groups: $51.2 \%$ were first lactation; $28.7 \%$, second, and $20.1 \%$, third lactation or greater. Heifers were calved at 26 to 28 months of age. The Northern California herd was well managed and well immunized. Milk production during the study period was about 22,500 pounds of milk and 880 pounds of butterfat. Death losses for 2-day- to 6month-old heifer calves born on the dairy averaged two calves per year of the study.

Measurements taken by dairy personnel were yield of colostrum at first milking, specific gravity of the colostrum and

\begin{tabular}{|c|c|c|c|c|c|c|c|c|}
\hline \multirow{3}{*}{$\frac{O_{F}}{102}$} & \multicolumn{7}{|c|}{ Specific Gravity } & \multirow{3}{*}{$\frac{{ }^{O} F}{102}$} \\
\hline & \multicolumn{2}{|c|}{ Poor } & \multicolumn{2}{|c|}{ Mediocre } & \multicolumn{3}{|c|}{ Best } & \\
\hline & 1.008 & 1.018 & 1.028 & 1.038 & 1.048 & 1.058 & 1.068 & \\
\hline 100 & 1.008 & 1.018 & 1.028 & 1.038 & 1.048 & 1.058 & 1.068 & 100 \\
\hline 98 & 1.009 & 1.019 & 1.029 & 1.039 & 1.049 & 1.059 & 1.069 & 98 \\
\hline 96 & 1.009 & 1.019 & 1.029 & 1.039 & 1.049 & 1.059 & 1.069 & 96 \\
\hline 94 & 1.010 & 1.020 & 1.030 & 1.040 & 1.050 & 1.060 & 1.070 & 94 \\
\hline 92 & 1.010 & 1.020 & 1.030 & 1.040 & 1.050 & 1.060 & 1.070 & 92 \\
\hline 90 & 1.011 & 1.021 & 1.031 & 1.041 & 1.051 & 1.061 & 1.071 & 90 \\
\hline 88 & 1.011 & 1.021 & 1.031 & 1.041 & 1.051 & 1.061 & 1.071 & 88 \\
\hline 86 & 1.012 & 1.022 & 1.032 & 1.042 & 1.052 & 1.062 & 1.072 & 86 \\
\hline 84 & 1.012 & 1.022 & 1.032 & 1.042 & 1.052 & 1.062 & 1.072 & 84 \\
\hline 82 & 1.012 & 1.022 & 1.032 & 1.042 & 1.052 & 1.062 & 1.072 & 82 \\
\hline 80 & 1.013 & 1.023 & 1.033 & 1.043 & 1.053 & 1.063 & 1.073 & 80 \\
\hline 78 & 1.013 & 1.023 & 1.033 & 1.043 & 1.053 & 1.063 & 1.073 & 78 \\
\hline 76 & 1.014 & 1.024 & 1.034 & 1.044 & 1.054 & 1.064 & 1.074 & 76 \\
\hline 74 & 1.014 & 1.024 & 1.034 & 1.044 & 1.054 & 1.064 & 1.074 & 74 \\
\hline 72 & 1.015 & 1.025 & 1.035 & 1.045 & 1.055 & 1.065 & 1.075 & 72 \\
\hline 70 & 1.015 & 1.025 & 1.035 & 1.045 & 1.055 & 1.065 & 1.075 & 70 \\
\hline 68 & 1.016 & 1.026 & 1.036 & 1.046 & 1.056 & 1.066 & 1.076 & 68 \\
\hline 66 & 1.016 & 1.026 & 1.036 & 1.046 & 1.056 & 1.066 & 1.076 & 66 \\
\hline 64 & 1.017 & 1.027 & 1.037 & 1.047 & 1.057 & 1.067 & 1.077 & 64 \\
\hline 62 & 1.017 & 1.027 & 1.037 & 1.047 & 1.057 & 1.067 & 1.077 & 62 \\
\hline 60 & 1.017 & 1.027 & 1.037 & 1.047 & 1.057 & 1.067 & 1.077 & 60 \\
\hline 58 & 1.018 & 1.028 & 1.038 & 1.048 & 1.058 & 1.068 & 1.078 & 58 \\
\hline 56 & 1.018 & 1.028 & 1.038 & 1.048 & 1.058 & 1.068 & 1.078 & 56 \\
\hline 54 & 1.019 & 1.029 & 1.039 & 1.049 & 1.059 & 1.069 & 1.079 & 54 \\
\hline 52 & 1.019 & 1.029 & 1.039 & 1.049 & 1.059 & 1.069 & 1.079 & 52 \\
\hline
\end{tabular}

*To use the table, find temperature in column at left or extreme right. Look for specific gravity range in between. For example, colostrum at $90^{\circ} \mathrm{F}$, reading 1.065 , would fall into the "Best" category. Notice that as temperature drops specific gravity of the colostrum increases. 
its temperature at time of the reading, colostrum appearance or color, and the number of hours from calving to first milking. The current number of lactations of each cow was recorded and used in the comparison groupings.

To facilitate comparisons of colostrum's specific gravity, which was measured at a wide range of temperatures, we established a relationship of temperature to specific gravity (table 1). This chart was developed to assist dairy personnel in converting the standard laboratory hydrometer and thermometer readings to a score which ranked colostrum's value, or immunoglobulin content.

Using the statistical software package SAS, we examined relationships between lactation number, color, hours to first milking, colostrum yield at first milking, and adjusted (102\%) specific gravity.

\section{Results}

Under the conditions of this study, there was no significant relationship between adjusted specific gravity and either colostrum color or yield at first milking. There was a low but negative correlation between adjusted specific gravity and hours between calving and first milking

TABLE 2. Color vs. number of hours from initation of calving to first milking

\begin{tabular}{lc}
\hline \hline Color & Hours \\
\hline White & $8.6 \mathrm{a}^{*}$ \\
Yellow & $7.2 \mathrm{~b}$ \\
Bloody or other & $6.8 \mathrm{~b}$ \\
\hline *Values followed by the same letter are not significantly \\
different from each other. \\
$\mathrm{P}^{2}=.0086$ & \\
$\mathrm{r}^{2}=.014$ &
\end{tabular}

TABLE 4. Milk yield at first milking vs. lactation

\begin{tabular}{lc}
\hline Lactation & Mean yield \\
3 or more & $18.0 \mathrm{ab}^{*}$ \\
2 & $19.3 \mathrm{a}$ \\
1 & $16.2 \mathrm{~b}$ \\
\hline${ }^{*}$ Values followed by the same letter are not significantly \\
different from each other. \\
$\mathrm{P}^{2}=.0001$ & \\
$\mathrm{r}^{2}=.027$ & \\
\end{tabular}

TABLE 6. Variability in measured observations

\begin{tabular}{lcccc}
\hline & Mean & $\begin{array}{c}\text { Standard } \\
\text { Deviation }\end{array}$ & $\begin{array}{c}\text { Minimum } \\
\text { Value }\end{array}$ & $\begin{array}{c}\text { Maximum } \\
\text { Value }\end{array}$ \\
\hline $\begin{array}{l}\text { Temperature at } \\
\text { time of measuring } \\
\left.\text { specific gravity ( }{ }^{\circ} \mathrm{F}\right)\end{array}$ & 82.5 & 9.66 & 42 & 100 \\
$\begin{array}{c}\text { Yield of colostrum } \\
\text { at first milking (lbs) }\end{array}$ & 17.43 & 8.39 & 2 & 59 \\
$\begin{array}{c}\text { Calving Time } \\
\text { to first milking (hrs) }\end{array}$ & 7.38 & 4.67 & 1 & 24 \\
$\begin{array}{c}\text { Specific gravity } \\
\text { adjusted to } 102^{\circ} \mathrm{F}\end{array}$ & 1,038 & 13.53 & 992 & 1,088 \\
\hline
\end{tabular}

(Pearson correlation coefficient $\mathrm{r}^{2}=0.18$ at 0.0001 probability level). There was a slight relationship $\left(r^{2}=0.014\right)$ between color of colostrum and hours to first milking as white colostrum was more prevalent when first milking was taken at a later time (table 2). A significant, but low correlation $\left(r^{2}=0.04\right)$ was observed between lactation number and adjusted specific gravity. Cows in their second and third lactations produced colostrum with a higher adjusted specific gravity than firstcalf heifers (table 3 ).

The relationship between colostrum yield at the first milking and lactation number was significant, but again the correlation $\left(\mathrm{r}^{2}=0.027\right)$ was low. Colostrum yield from the first milking was greater for cows beginning second and third lactations (table 4).

If yellow were assumed to be a normal color for colostrum taken at the first milking, there was significantly more "abnormal" milk produced by the third lactation cows than by the first and second lactation cows (table 5). The average temperature at time of measuring specific gravity was $12^{\circ} \mathrm{F}$ above the standard $72^{\circ} \mathrm{F}$ level used for the colostrometer, and ranged from about $30^{\circ} \mathrm{F}$ above to $30^{\circ} \mathrm{F}$ below the $72^{\circ} \mathrm{F}$

TABLE 3. Lactation vs. adjusted specific gravity

\begin{tabular}{ll}
\hline Lactation & Adjusted specific gravity \\
\hline 3 or more & $1042.4 \mathrm{a}^{*}$ \\
2 & $1039.6 \mathrm{a}$ \\
1 & $1035.7 \mathrm{~b}$ \\
\hline \multirow{2}{*}{ Values followed by the same letter are not significantly }
\end{tabular}
different from each other.

$P=.0001$

$r^{2}=.040$

TABLE 5. Color vs. lactation number

\begin{tabular}{|c|c|c|c|}
\hline \multirow[t]{2}{*}{ Color } & \multicolumn{3}{|c|}{ Lactation } \\
\hline & 1 & 2 & 3 \\
\hline Bloody or other & 12.16 & 10.14 & 18.62 \\
\hline White & 14.05 & 16.43 & 20.69 \\
\hline Yellow & 73.73 & 73.43 & 60.69 \\
\hline
\end{tabular}

$\mathrm{P}=.0074$ for color lactation 1 or 2 vs, color lactation 3

\begin{tabular}{|lc|}
\hline \multicolumn{2}{|c|}{ TABLE 7. Lactation vs. temperature } \\
\hline \hline Lactation & Mean \\
\hline \multirow{3}{*}{ or more } & OF \\
2 & 83.3 \\
1 & 84.1 \\
\hline
\end{tabular}

level (table 6). The average adjusted specific gravity of the colostrum at first milking in this herd study would be classified as mediocre in estimated concentration of immunoglobulins. Though immunoglobulin levels were significantly better for second and third or more lactations, the level of improvement was small (table 3 ).

When measured for specific gravity, comparisons between lactation number and temperature of the colostrum were not significantly different, indicating similar management for these groups.

\section{Conclusions}

There were significant relationships among lactation number, color of colostrum at first milking, adjusted specific gravity, the production of abnormal appearing colostrum (other than yellow), and yields of colostrum at the first milking. There was also a significant relationship between color and hours to first milking. However, the correlations were quite low, indicating that other factors not identified in the study had a higher level of influence.

There were no significant relationships between unadjusted or temperature-adjusted specific gravity and either colostrum color or yield at first milking. Therefore, color characteristics often used to describe colostrum quality should not be used to judge the concentration of immunoglobulins in the first milk or its usefulness as a means of developing passive immunity in newborn calves.

The use of temperature adjusted specific gravity criteria for evaluation increased the credibility of the specific gravity reading among dairy personnel. Conversion tables requiring thermometer readings as well as a hydrometer reading provided the highest level of usefulness when wide ranging temperatures were experienced. The extremely low correlations among other measured relationships suggest that the only dependable means of evaluating colostrum for its immunoglobulin concentration would be direct measurement of specific gravity adjusted by temperature.

D. A. Toenjes is Farm Advisor, Glenn Co.; S. Strasser is Programmer/Analyst, and D. L. Bath is Dairy Nutritionist, UC Davis.

The authors wish to thank the LaGrone Dairy owners and herd managers for their dedication of time and resources to this study. 